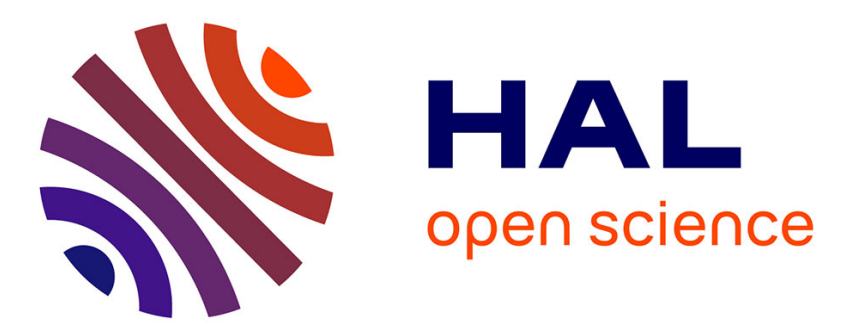

\title{
Reconstruction of perfect $\mathrm{ZnO}$ nanowires facets with high optical quality
}

E. Zehani, S. Hassani, A. Lusson, J. Vigneron, A. Etcheberry, P. Galtier, V. Sallet

\section{- To cite this version:}

E. Zehani, S. Hassani, A. Lusson, J. Vigneron, A. Etcheberry, et al.. Reconstruction of perfect $\mathrm{ZnO}$ nanowires facets with high optical quality. Applied Surface Science, 2017, 411, pp.374-378. 10.1016/j.apsusc.2017.03.201 . hal-02972522

\section{HAL Id: hal-02972522 \\ https://hal.science/hal-02972522}

Submitted on 20 Nov 2020

HAL is a multi-disciplinary open access archive for the deposit and dissemination of scientific research documents, whether they are published or not. The documents may come from teaching and research institutions in France or abroad, or from public or private research centers.
L'archive ouverte pluridisciplinaire HAL, est destinée au dépôt et à la diffusion de documents scientifiques de niveau recherche, publiés ou non, émanant des établissements d'enseignement et de recherche français ou étrangers, des laboratoires publics ou privés. 


\title{
Reconstruction of perfect $\mathrm{ZnO}$ nanowires facets with high optical quality
}

\author{
E. Zehani ${ }^{1}$, S. Hassani ${ }^{1}$, A. Lusson ${ }^{1}$, J. Vigneron ${ }^{2}$,
}

A. Etcheberry ${ }^{2}$, P. Galtier ${ }^{1}$, and V. Sallet ${ }^{1 *}$.

${ }^{1}$ Université Paris-Saclay, CNRS, Université de Versailles St Quentin en Yvelines, Groupe d'Etude de la Matière Condensée (GEMAC), 45 avenue des Etats Unis, 78035 Versailles France.

2 Université Paris-Saclay, CNRS, Université de Versailles St Quentin en Yvelines, Institut Lavoisier de Versailles (ILV), 45 avenue des Etats Unis, 78035 Versailles France.

*Email: vincent.sallet@uvsq.fr; phone: 331392544 88; fax: 33139254652

Keywords $\mathrm{ZnO}$ nanowires, annealing, photoluminescence, surface exciton, XPS

\begin{abstract}
$\mathrm{ZnO}$ nanowires were grown on sapphire substrates using metalorganic chemical vapor deposition. The samples were subsequently annealed under zinc pressure in a vacuum-sealed ampoule, at temperature ranging from 500 to $800^{\circ} \mathrm{C}$. The originality and the main motivation to provide a zinc-rich atmosphere were to prevent the out-diffusion of zinc from the nanowires. In doing so, the perfect structural properties and the morphology of the nanowires are kept. Interestingly, photoluminescence experiments performed on nanowires annealed in a narrow window of temperature $\left[580-620^{\circ} \mathrm{C}\right]$ show a spectacular improvement of the optical quality, as transitions commonly observable in high quality bulk samples are found. In addition, the intensity of the so-called "surface excitons" (SX) is strongly decreased. To accurately investigate the chemical modifications of the surface, XPS experiments were carried out and show that zinc hydroxide species and/or $\mathrm{Zn}(\mathrm{OH})_{2}$ sublayer were partially removed from the surface. These results suggest that the annealing process in zinc vapor helps to properly reconstruct the surface of $\mathrm{ZnO}$ nanowires, and improves the optical quality of their core. Such a thermal treatment at moderate temperature should be beneficial to nanodevices involving surface reaction, e.g. gas sensors.
\end{abstract}




\section{Introduction}

Semiconductor nanowires (NWs) are attractive building blocks for a new generation of electronic and opto-electronic devices, as well as gas sensors and nanogenerators. The last decades have shown the accurate control of the electrical properties of bulk materials and thin films, and more recently the evolution of the research towards nanotechnologies made possible both p-type and n-type conductions in 1D nanostructures (nanowires) based on silicon and III$\mathrm{V}$ semiconductors [1]. In addition to these materials, $\mathrm{ZnO}$ is a II-VI compound which has demonstrated a great potential due a unique combination of physical properties, as well as an ability to be grown at the nanometer scale by using a variety of techniques $[2,3]$ such as chemical vapor deposition (CVD) [4], metalorganic-CVD [5], molecular beam epitaxy [6], pulse laser deposition [7]. High quality material can also be achieved using low-cost techniques, e.g. electrodeposition [8] and hydrothermal synthesis [9], thus making $\mathrm{ZnO}$ a potential candidate for the future development of semiconductor-based nanodevices [10]. In particular, $\mathrm{ZnO}$ takes benefit of a direct wide band gap (3.37 eV) and a high exciton binding energy (60 $\mathrm{meV}$ ). In order to introduce donors or acceptors, $\mathrm{ZnO}$ NWs have been doped with various impurities such as Al, Ga, In [11] (towards n-type) and N [12], P [13], Sb [14], As [15] (towards p-type). Nevertheless, for light-emitting applications, the achievement of stable and reproducible p-type conduction is still a bottleneck, due to high activation energies and selfcompensation effect of intrinsic defects [16]. Importantly, a main feature of $\mathrm{ZnO}$ material concerns its very reactive surface, highly sensitive to gases such as $\mathrm{NO}_{\mathrm{x}}, \mathrm{CO}$ and $\mathrm{NH}_{3}$. The sensing mechanism is a surface reaction that leads to the modification of the conductance of the nanostructure, relying on the interaction between reactive species on the $\mathrm{ZnO}$ surface (such as $\mathrm{O}_{2}^{-}$) and the detected gas [17].

Within this context, it is important to understand the influence of the surface on the electrical and optical properties of $\mathrm{ZnO}$ nanowires which exhibit high surface-to-volume ratio. Using photoluminescence (PL), it has been reported that an emission band between 3.365 and 3.367 $\mathrm{eV}$, denoted SX, takes its origin from the surface region of $\mathrm{ZnO}$ [18-21], i.e. the exciton is localized on the potential of a surface defect and/or adsorbed impurity. However the nature of the surface defects responsible for the SX band is not easy to understand. Among the very few reported works, Biswas and al emphasized the role of zinc hydroxides on the SX emission [22]. $\mathrm{SX}$ intensity is also shown to increase by covering $\mathrm{ZnO}$ surface with organic monolayer [23] or $\mathrm{Al}_{2} \mathrm{O}_{3}$ shell [24].

Besides, in an attempt to modify the surface properties of $\mathrm{ZnO}$, a huge variety of annealing experiments can be found in the literature. Thermal treatments were performed after growth 
under oxygen, air, nitrogen and argon atmosphere at relatively high temperatures up to $1200{ }^{\circ} \mathrm{C}$ [25-27]. Surprisingly, there are very few works dealing with annealing treatments in Zn vapor. Actually, one must not only care for oxygen out-diffusion during thermal treatment, but also zinc out-diffusion [28]. Studies related to the thermal treatment of $\mathrm{ZnO}$ in zinc vapor were mainly interested in the characterization of intrinsic defects in $\mathrm{ZnO}$ crystals. Weber et al [29] and Halliburton et al [30] have observed a red coloration of $\mathrm{ZnO}$ crystals after annealing in $\mathrm{Zn}$ vapor at $1100^{\circ} \mathrm{C}$, and several origins have been proposed : complexes involving hydrogen and oxygen vacancy [29] or zinc interstitials [30]. Furthermore, there are very few reports giving near band edge emission (NBE) details and focusing on SX transition after thermal treatment, whatever the annealing atmosphere. Rather, the deep level emission (DLE) has been investigated in relation with zinc and oxygen vacancies [31]. As a result, the motivation of this work has been to investigate the structural and the optical properties of $\mathrm{ZnO}$ nanowires grown by MOCVD and post-annealed in the presence of $\mathrm{Zn}$ vapor, focusing on the surface related phenomena.

\section{Experiments}

Non-intentionally doped $\mathrm{ZnO}$ nanowires were grown on (11-20) a-plane sapphire substrates using an atmospheric MOCVD system including a vertical quartz reactor. Diethylzinc (DEZn) and nitrous oxide $\left(\mathrm{N}_{2} \mathrm{O}\right)$ have been used as zinc and oxygen precursors, respectively. The carrier gas was helium. Partial pressures of DEZn and $\mathrm{N}_{2} \mathrm{O}$ in the gas phase were set at 92 and 37000 $\mathrm{Pa}$, respectively. The growth temperature was $850{ }^{\circ} \mathrm{C}$, and growth time was $15 \mathrm{~min}$.

After growth, the $\mathrm{ZnO}$ nanowires samples were inserted in quartz tubes together with $\sim 30 \mathrm{mg}$ of $5 \mathrm{~N}$ pure $\mathrm{Zn}$ powder. The ampoules were subsequently sealed under vacuum, below $2 \times 10^{-7}$ torr. Figure 1 shows the schematic view of an ampoule prepared for the thermal treatment. The samples were then annealed for $5 \mathrm{~h}$ at a temperature ranging from 500 to $800{ }^{\circ} \mathrm{C}$. Before and after experiments, the morphology of the nanowires was assessed using a JEOL 7001F scanning electron microscope (SEM). Photoluminescence measurements were also carried out at $5 \mathrm{~K}$ using the $351 \mathrm{~nm}$ UV line of an argon ion laser. The chemical evolution of the surface was examined by X-ray Photoelectron Spectroscopy (XPS) using a Thermo Scientific K-Alpha system. 


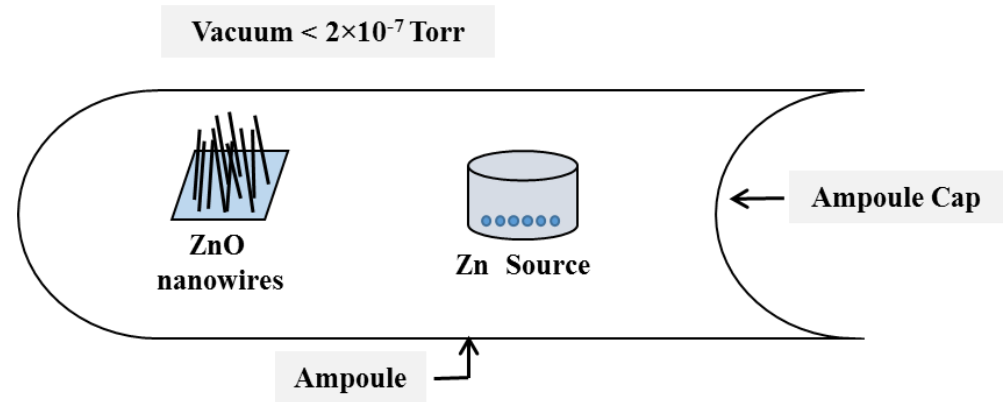

Figure 1 Schematic view of a sealed ampoule, prepared for the annealing in zinc vapor

\section{Results and discussion}

Figure 2 shows the SEM images of as-grown and annealed $\mathrm{ZnO}$ nanowires, and for this latter case with and without $\mathrm{Zn}$ atmosphere during $5 \mathrm{~h}$ at $700{ }^{\circ} \mathrm{C}$. The average length of the nanowires is around $13 \mu \mathrm{m}$ and their diameter is in the range of 500 to $1000 \mathrm{~nm}$. The NWs are grown along the (0001) c-direction with clear facets on their sides. When processed in zinc vapor, the annealed samples show no macroscopic degradation of their surface and morphology up to $800^{\circ} \mathrm{C}$, but may exhibit different contents of point defects. This will be discussed in the next part. The degradation occurs if the annealing is performed without zinc source, as figure $2 \mathrm{c}$ reveals a drastic damage of the nanowires above $700^{\circ} \mathrm{C}$. This could be due to a strong zinc outdiffusion from $\mathrm{ZnO}$ at high temperature, as reported by Wang et al [28], and, to a much lower extent, oxygen diffusion that was shown to create high concentrations of oxygen vacancies [31].
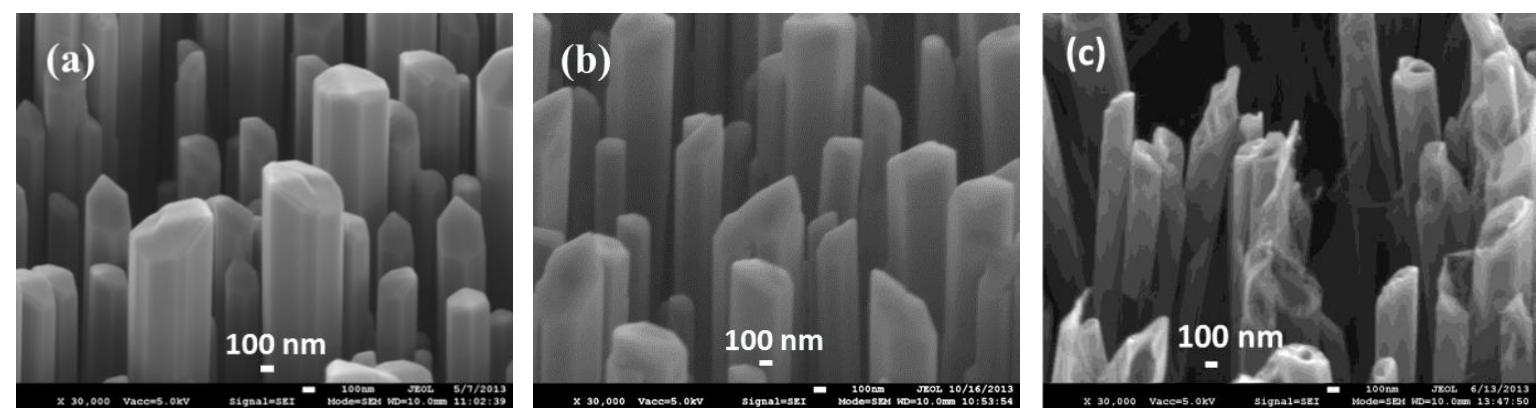

Figure $2 \mathrm{SEM}$ images of $\mathrm{ZnO}$ nanowires

(a) as-grown, (b) post-annealed with $\mathrm{Zn}$ at $700{ }^{\circ} \mathrm{C}$, (c) post-annealed without $\mathrm{Zn}$ at $700{ }^{\circ} \mathrm{C}$.

Figure 3 presents the evolution of photoluminescence spectra recorded on as-grown and annealed NWs. The PL emission of the as-grown nanowires is dominated by the surface recombination (SX) at $3.367 \mathrm{eV}$. Additional transitions can be distinguished involving excitons bound to $\mathrm{Al}$ and $\mathrm{H}$ impurities at $3.372 \mathrm{eV}\left(\mathrm{D}^{+} \mathrm{X}(\mathrm{Al})\right), 3.362 \mathrm{eV}\left(\mathrm{D}^{\circ} \mathrm{X}(\mathrm{H})\right)$, and $3.360 \mathrm{eV}$ 
$\left(\mathrm{D}^{\circ} \mathrm{X}(\mathrm{Al})\right)[32]$. These peaks are followed by the $\mathrm{Y}$-line at $3.333 \mathrm{eV}$ which is related to excitons bound to extended defects [32], and an electron-acceptor band at $3.31 \mathrm{eV}$ also related to defects [33]. The free exciton FX is hardly seen at $3.375 \mathrm{eV}$.

As discussed in the introduction part, the observation of surface excitons is consistent with the increased surface-to-volume ratio, and characteristic of the nanowires [34]. After annealing at low temperature, below $550{ }^{\circ} \mathrm{C}$, PL spectra of $\mathrm{ZnO}$ nanowires remain unchanged compared with as-grown reference. For treatments between 580 and $620^{\circ} \mathrm{C}$, and only within this narrow range of temperature, we observe a strong improvement of the PL spectrum which is comparable to PL spectra obtained for high quality bulk $\mathrm{ZnO}$ crystals (figure $3 \mathrm{~b}$ ). A fine structure of the near band edge emission is revealed, with well-defined narrow lines in the range 3.35-3.37 eV. The peaks related to excitons bound to $\mathrm{Al}$ and $\mathrm{H}$ donor impurities, as well as the free exciton structures at higher energy, clearly dominate the SX emission. Indeed, the $\mathrm{I}_{6}$ line at $3.360 \mathrm{eV}$ related to aluminum impurities is dominant after annealing whereas the intensity of SX band has strongly decreased. Aluminium contamination may come from sapphire substrates during the MOCVD growth at $850^{\circ} \mathrm{C}$. Remaining defect lines could be explained by extended defects still present at the bottom of the nanowires, close to the interface with sapphire substrate. Above $620^{\circ} \mathrm{C}$ the benefits of the annealing on the PL emission seem to fade, as the fine structure of the NBE emission is no more observable and SX intensity increases (not shown here). Interestingly, for the $\mathrm{ZnO} N W$ s which had been treated at $620^{\circ} \mathrm{C}$, the initial PL spectrum is recovered and SX peak dominates again after the sample has been stored for two months, i.e. exposed to air atmosphere for a long time.

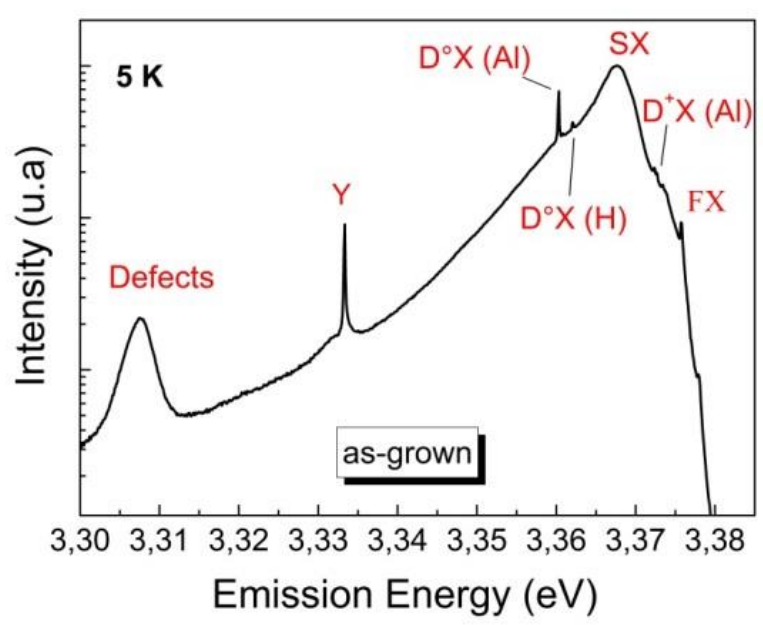

a) 


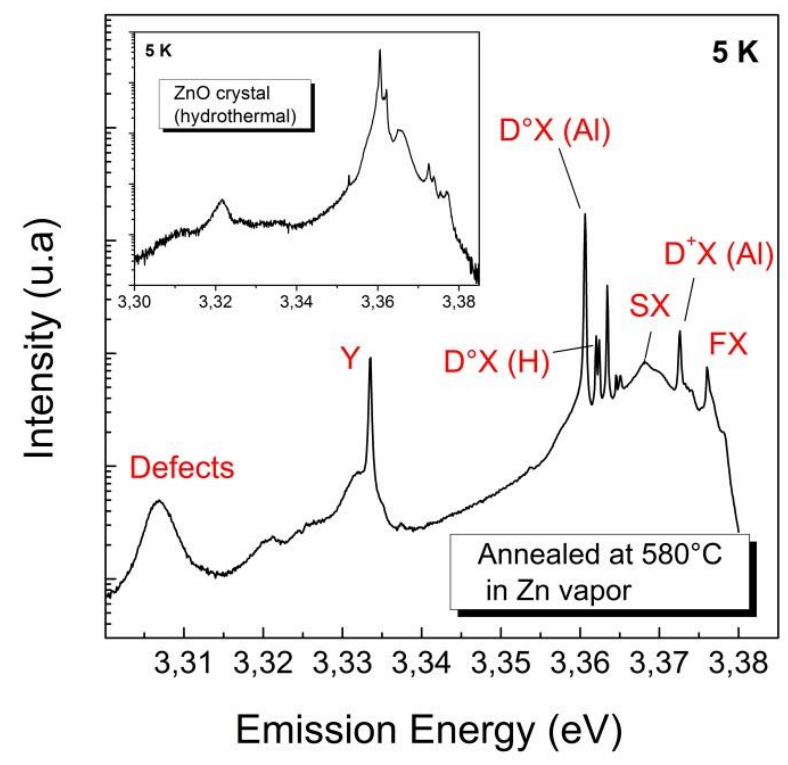

b)

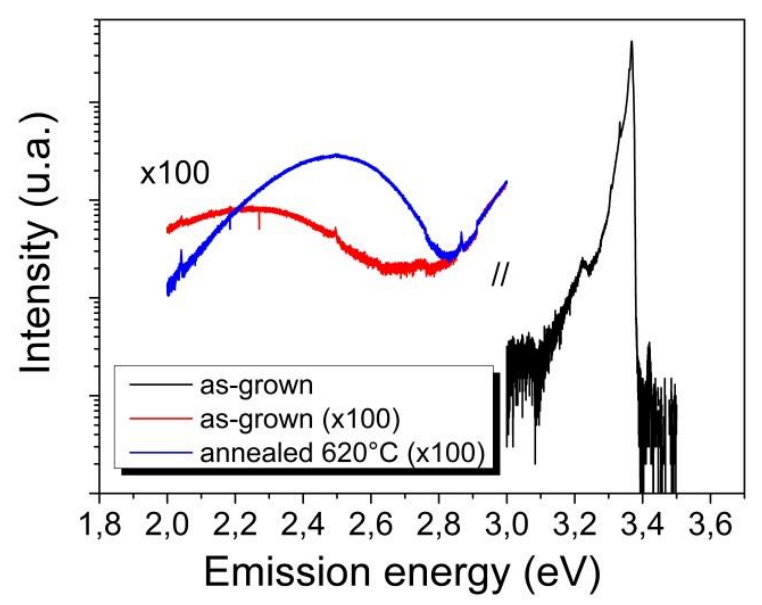

c)

Figure $3 \mathrm{PL}$ spectra measured at $5 \mathrm{~K}$ for $\mathrm{ZnO}$ nanowires samples: a) as grown, b) treatment at $580{ }^{\circ} \mathrm{C}$ under $\mathrm{Zn}$ source (insert : $\mathrm{ZnO}$ crystal), c) near band edge emission of as-grown (black), and deep level emissions of as-grown (red) and annealed at $620^{\circ} \mathrm{C}$ (blue). For DLE bands, the integration time has been increased and filters changed to enhance the PL signals

As a result, $\mathrm{ZnO}$ nanowires thermally treated in a narrow window of temperature under zinc atmosphere show a significant improvement of their optical properties, and in particular a decrease of the surface related exciton emission. Previous reports have focused on photoluminescence studies after the annealing of $\mathrm{ZnO}$ NWs. The improvement of the optical quality depends on the technique that had been used to grow the NWs [35]. The NBE intensity is shown to increase significantly [36] and/or to lead to a narrowing of the NBE transitions [8]. 
The benefit of the annealing is often stronger for nanowires grown at low temperature using chemical bath deposition, or electrodeposition. In that case the improvement of the optical quality can be related to a strong improvement of the crystalline quality of the grown material. The effect on the DLE has also been observed. At reduced temperature $\left(500^{\circ} \mathrm{C}\right)$, a decrease was reported by Yang et al [36], thus lowering the concentration of surface and lattice defects. However at higher temperature, the DLE can increase due to thermal diffusion and creation of point defects. In this work, we observed for as-grown samples that the DLE intensity is very weak, more than three orders of magnitude lower than the NBE intensity, as shown in the figure $3 \mathrm{c}$. This indicates the high quality of our as-grown material. After annealing at $620^{\circ} \mathrm{C}$, the level of the DLE slightly increases with a noticeable blue-shift from $\sim 2.25$ to $\sim 2.5 \mathrm{eV}$ which can be related to both creation of oxygen vacancies and reduction of zinc vacancies [31]. However the intensity of the DLE remains very low.

Herein, we could identify each recombination path in the NBE region so that we have been able to focus on the particular SX emission. To rigorously investigate the chemical modifications of the NWs surface due to the annealing process, X-ray Photoelectron Spectroscopy has been carried out. Four samples were measured : i) as-grown $\mathrm{ZnO} \mathrm{NWs}$, ii) annealed at $550^{\circ} \mathrm{C}$, iii) annealed at $620^{\circ} \mathrm{C}$ and iv) annealed at $620^{\circ} \mathrm{C}+2$ months aging.

The global XPS responses were very reproducible and did not need any charge compensation during the acquisition. At first, it is important to note that the position and the energy distribution of the $\mathrm{Zn} 2 \mathrm{p}_{3 / 2}$ peaks are rigorously the same for all the investigated surfaces. The binding energies of the $\mathrm{Zn} 2 \mathrm{p}_{3 / 2}$ peaks are $1022.33+/-0.02 \mathrm{eV}$ which is however slightly higher than the value obtained for $\mathrm{ZnO}$ monocrystalline face (typically $1021.8 \mathrm{eV}$ [37]). The full width at half maximum (FWHM) values of these peaks are nearly identical to the one observed on planar $\mathrm{ZnO}$ crystals. In the same way the $\mathrm{O}_{1 \mathrm{~s}}$ maximum is centered at $531.07+/-0.02 \mathrm{eV}$ compared to $530.6 \mathrm{eV}$ obtained on $\mathrm{ZnO}$ crystals. Therefore, the energy difference between $\mathrm{Zn} 2 \mathrm{p}_{3 / 2}$ and $\mathrm{O}_{1 \mathrm{~s}}$ peaks is the same as the one observed on monocrystal faces, suggesting a high quality of the NWs.

The XPS results are gathered in the figure 4, and quantifications are given in the table 1 . The $\mathrm{O}_{1 s}$ spectra display a significant evolution upon the different treatments of samples, with a clear reduction of the peak shoulder, whereas the $\mathrm{Zn}_{2} \mathrm{p}_{3 / 2}$ spectra do not show any modification (not shown here). 
To separate and analyze the different contributions, the $\mathrm{O}_{1 s}$ spectra were fitted with three peaks, with binding energies at 531, 532.4 and $533.3 \mathrm{eV}$. All the FWHMs were kept constant, the value being determined by the main $\mathrm{O}-\mathrm{Zn}$ peak, which is easily determined and almost constant whatever the treatment of the sample. The fit allows the reconstruction of the whole $\mathrm{O}_{1 \mathrm{~s}}$ distribution and indicates the presence of particular oxygen-bonding states at the surface. The main peak at $531 \mathrm{eV}$ is attributed to oxygen atoms bound to zinc $(\mathrm{Zn}-\mathrm{O})$ in the wurzite $\mathrm{ZnO}$ lattice. The binding energy of $\mathrm{O}^{2-}$ ions depends on the ionicity or covalency of the chemical bound, so that adsorbed molecules on the NWs surface such as - $\mathrm{OH}$ and $-\mathrm{CO}$ groups will cause the appearance of a second peak at $532.4 \mathrm{eVs}$ peak [37]. Also, a contribution is related to nonstoichiometric $\mathrm{ZnO}$ surface planes, leading to a weaker $\mathrm{Zn}-\mathrm{O}$ bond. In particular, an oxygendeficient region has been suggested by Wang et al, after they have annealed $\mathrm{ZnO}$ nanoparticules in argon atmosphere and observed a strong increase of this peak [38]. At higher energy (533.3 $\mathrm{eV})$, a third peak was reported to be related to zinc hydroxide chemical bound $\left(\mathrm{Zn}(\mathrm{OH})_{2}\right)$ and adsorbed water [39]. In figure 5, the intensity ratio between the hydroxide peak at $533.3 \mathrm{eV}$ and the $\mathrm{O}_{\text {lattice }}$ peak at $531 \mathrm{eV}$ is plotted. We observe that the intensity ratio decreases after annealing, especially at $620^{\circ} \mathrm{C}$, and increases again after aging in ambient air, exhibiting the same tendency as SX peak intensity in PL results. For more accuracy, a quantification of the $\mathrm{Zn}-(\mathrm{OH})_{2} \mathrm{XPS}$ peak is given in the table 1, and the level is shown to decrease from 4.1 to $2.8 \%$ after annealing, and then return to $4.3 \%$ after aging. One can notice that no change in the intensity of the $532.4 \mathrm{eV}$ peak related to, $-\mathrm{OH},-\mathrm{CO}$ and non-stoechiometric region has been observed. In addition, the quantification of carbon atoms on the surface has been measured between 7 and $15 \%$. These values are typical of $\mathrm{ZnO}$ surface and reflect the carbon contamination $(\mathrm{C}-\mathrm{C}, \mathrm{C}=\mathrm{O}, \mathrm{H}-\mathrm{O}-\mathrm{C}=\mathrm{O} \ldots)$ after air exposure. One can even emphasize that the sticking of carbon molecules on our $\mathrm{ZnO}$ NWs arrays is rather low, as compared to the reference $\mathrm{ZnO}$ crystal which exhibits $16.6 \%$ of $\mathrm{C}$ on its surface. No tendency was found regarding this adsorption of organic molecules upon annealing for the different series of samples.

Therefore, there is a correlation between the decreasing of SX intensity and the amount of hydroxide $\mathrm{Zn}(\mathrm{OH})_{2}$ on the nanowires surface. The origin of SX could be, at least partially, explained by the occurrence of these species on the $\mathrm{ZnO}$ surface. This is in agreement with previously reported results from Biswas et al [22]. During the thermal treatment under zinc atmosphere we infer that a decomposition of zinc hydroxide occurs, following the reaction :

$\mathrm{Zn}(\mathrm{OH})_{2} \rightarrow \mathrm{ZnO}+\mathrm{H}_{2} \mathrm{O}$ 
Such a phase transformation from $\mathrm{Zn}(\mathrm{OH})_{2}$ to $\mathrm{ZnO}$ has also been reported by Duchoslav et al [40] and Wang et al [41]. At the same time, the thermal process allows the reconstruction of clean perfect $\mathrm{ZnO}$ facets with a reduced concentration of defects, thus decreasing SX emission. In this process the limitation of zinc exo-diffusion from $\mathrm{ZnO}$ nanowires could help. $\mathrm{Zn}$ vapor may be also beneficial to the optical properties of the NWs body, as sharp excitonic emissions are seen in the PL spectra. Interestingly, in this range of temperature, no oxygen supply is required to achieve high optical quality $\mathrm{ZnO}$ nanowires. Although oxygen vacancies are created, the DLE intensity is kept very low, as compared with the NBE intensity.
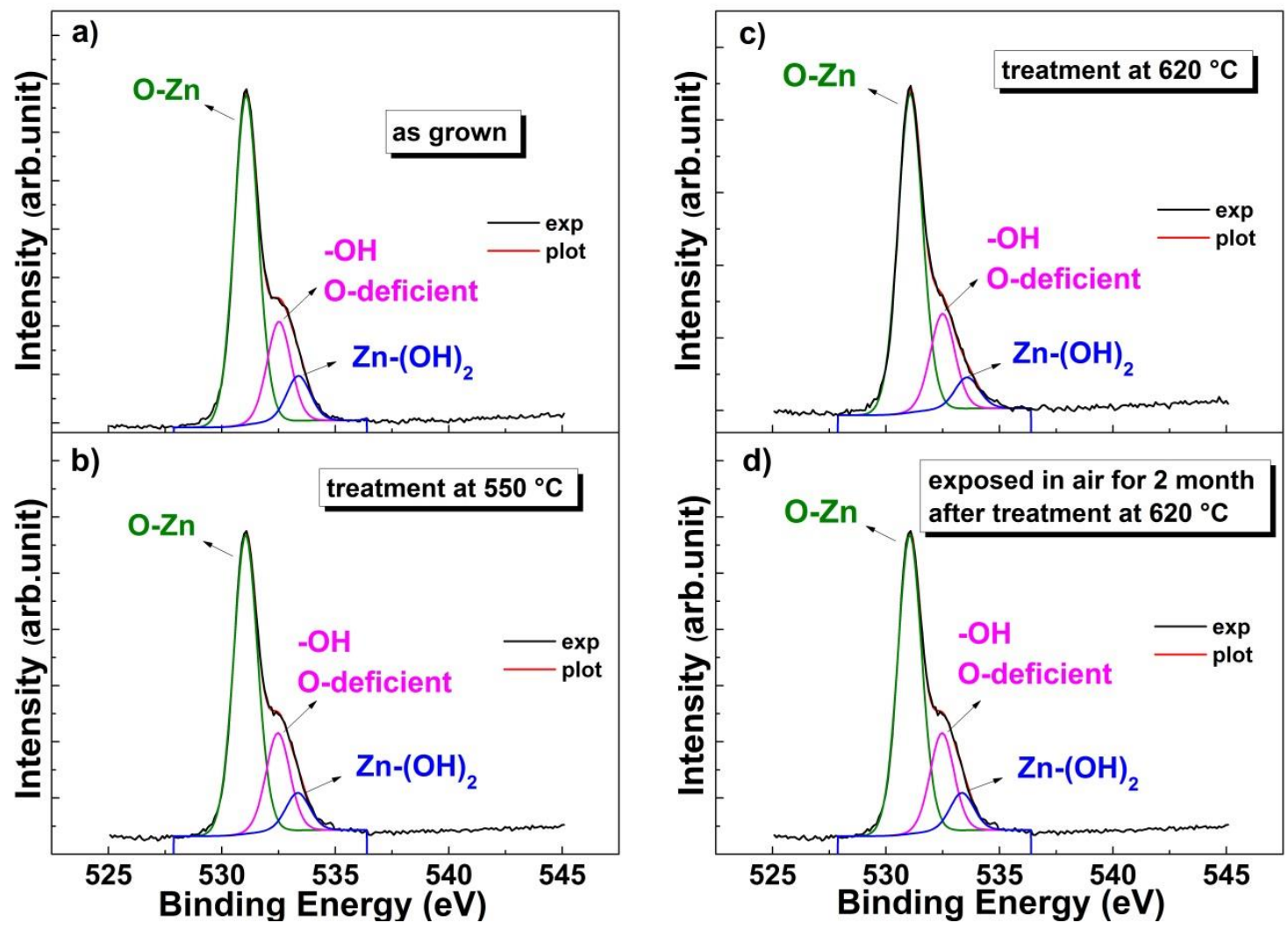

Figure 4 Peak fitted XPS $\mathrm{O}_{1 \mathrm{~s}}$ spectra for different treatments:

(a) as grown (b) post-annealed at $550{ }^{\circ} \mathrm{C}$ (c) post-annealed at $620^{\circ} \mathrm{C}$ (d) exposed to air for 2 month after treatment at $620{ }^{\circ} \mathrm{C}$. 


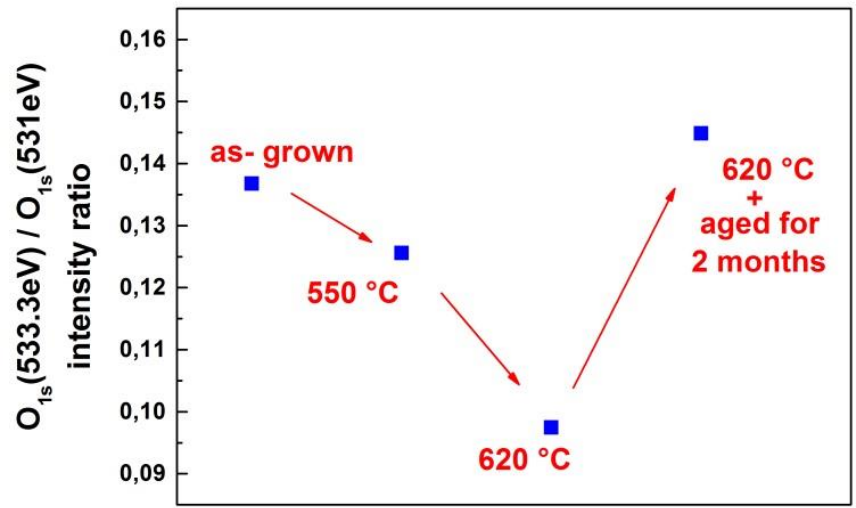

Figure 5 Intensity ratio between $(533.3 \mathrm{eV})$ - and $(531 \mathrm{eV})-\mathrm{O}_{1 \mathrm{~s}}$ peaks for the different treated samples

\begin{tabular}{|c|c|c|c|c|c|}
\hline & $\begin{array}{c}Z n 2 p_{3 / 2} \\
1022,3 e V\end{array}$ & $\begin{array}{c}O-Z n \\
531 e V\end{array}$ & $\begin{array}{c}\mathrm{OH} \\
\text { O-deficient } \\
\text { region } \\
532.4 \mathrm{eV}\end{array}$ & $\begin{array}{c}\mathrm{Zn}-(\mathrm{OH})_{2} \\
533.3 e V\end{array}$ & $\begin{array}{c}C_{1 s} \\
286-289 e V\end{array}$ \\
\hline ZnO crystal (hydroth.) & 41.3 & 33.4 & 6 & 2.6 & 16.6 \\
\hline as grown & 50 & 29.9 & 9.1 & 4.1 & 6.9 \\
\hline $550{ }^{\circ} \mathrm{C}$ & 48.3 & 28.9 & 9.5 & 3.6 & 9.6 \\
\hline $620^{\circ} \mathrm{C}$ & 44.2 & 29.05 & 8.7 & 2.8 & 15.2 \\
\hline $\begin{array}{l}620^{\circ} \mathrm{C}+\text { aged } \\
\text { for } 2 \text { months }\end{array}$ & 42.4 & 29.4 & 10.7 & 4.3 & 13.2 \\
\hline
\end{tabular}

Table 1 Quantification of XPS Zn2p $\mathrm{p}_{3 / 2}, \mathrm{O}_{1 \mathrm{~s}}$, and $\mathrm{C}_{1 \mathrm{~s}}$ peak (atm.\%) 


\section{Conclusion}

A strong improvement of the optical quality is observed for $\mathrm{ZnO}$ nanowires samples after thermal treatment in zinc vapor carried out between 580 and $620{ }^{\circ} \mathrm{C}$, thus at moderate temperature compared with the usual temperature reported in the literature. The PL emission due to surface excitons is decreased in the favor of a fine NBE structure similarly observed in high quality $\mathrm{ZnO}$ bulk crystals. This improvement of the surface chemistry is associated with the reduction of hydroxide species and/or $\mathrm{Zn}(\mathrm{OH})_{2}$ sublayer present on the surface after the growth of nanowires. The results suggest that the annealing process of $\mathrm{ZnO}$ nanowires enables to reconstruct clean M-plane facets and further increases the optical quality of the body, as sharp excitonic emission lines are observed. A moderate increase of the concentration of oxygen vacancies is nevertheless induced and the weakly intense DLE band shifts from 2.25 to $2.5 \mathrm{eV}$. Hence, we emphasize the role of surface physical-chemistry in the optical properties of $\mathrm{ZnO}$ nanowires. Such surface reconstruction could be helpful before integrating $\mathrm{ZnO}$ nanowires into nanodevices based on surface reactions, like gas sensors.

Acknowledgements : this work was supported by the French "Agence Nationale de la Recherche", project n ${ }^{\circ}$ ANR-11-NANO-013 


\section{References}

[1] J. Wallentin, and M.T. Borgström, Journal of Materials Research, 26 (17) 2142 (2011).

[2] D. P. Singh, Sci. Adv. Mater 2, 245 (2010).

[3] A.B. Djurisic, A.M.C. Ng, and X.Y. Chen, Progress in Quantum Electronics 34, 191 (2010).

[4] H. Wan and H.E. Ruda, J Mater Sci: Mater Electron 21, 1014 (2010).

[5] D.N. Montenegro, A.Souissi, C.Martinez-Tomas, V.Muñoz-Sanjose, V.Sallet, Journal of Crystal Growth 359, 122 (2012).

[6] M.A. Pietrzyk, M. Stachowicz, A. Wierzbicka, P. Dluzewski, D. Jarosz, E. Przezdziecka, A. Kozanecki, Journal of Crystal Growth 408, 102 (2014).

[7] J Zuñiga-Perez, A Rahm, C Czekalla, J Lenzner, M Lorenz and M Grundmann, Nanotechnology 18, 195303 (2007).

[8] O. Lupan, T. Pauporté, L. Chow, G. Chai, B. Viana, V.V. Ursaki, E. Monaico, I.M. Tiginyanu, Applied Surface Science 259, 399 (2012).

[9] V. Consonni, E. Sarigiannidou, E.Appert, A. Bocheux, S. Guillemin, F. Donatini, I.C. Robin, J. Kioseoglou, and F. Robaut, ACS Nano 20148 (5), 4761.

[10] M. Willander, O. Nur, Q.X. Zhao, L.L. Yang, M. Lorenz, B.Q. Cao, J. Zúñiga Pérez, C. Czekalla, G. Zimmermann, M. Grundmann, A. Bakin, A. Behrends, M. Al-Suleiman, A. ElShaer, A. Che Mofor, B. Postels, A. Waag, N. Boukos, A. Travlos, H. S. Kwack, J. Guinard and D. Le Si Dang, Nanotechnology 20, 332001 (2009).

[11] S.J. Young, C.C. Yang and L.T. Lai, J. Electrochem. Soc. 164, issue 5, B3013, (2017).

[12] A. Marzouki, F. Falyouni, N. Haneche, A. Lusson, P. Galtier, L. Rigutti, G. Jacopin, M. Tchernycheva, M. Oueslati, V. Sallet, Materials Letters 64, Issue 19, 2112 (2010).

[13] B Q Cao, M Lorenz, A Rahm, H von Wenckstern, C Czekalla, J Lenzner, G Benndorf and M Grundmann, Nanotechnology 18, 455707 (2007).

[14] Sheng Chu, Guoping Wang, Weihang Zhou, Yuqing Lin, Leonid Chernyak, Jianze Zhao, Nature Nanotechnology 6, 506 (2011)

[15] J.Y. Zhang, P.J. Li, H. Sun, X. Shen, T.S. Deng, K.T. Zhu, Q.F. Zhang, and J.L. Wu, Appl. Phys. Lett. 93, 021116 (2008).

[16] D. C. Look, Doping and Defects in ZnO, edited by C. Jagadish and S. Pearton, ZnO Oxide Bulk, Thin Films and Nanostructures: Processing, Properties and Applications (Elsevier, Amsterdam, 2006).

[17] S. K. Gupta, A. Joshi and M. Kaur, J. Chem. Sci. 122, 57 (2010). 
[18] Q.X. Zhao, L.L. Yang, M. Willander, B.E. Sernelius, and P.O. Holtz, J. Appl. Phys. 104, 073526 (2008).

[19] L. Wischmeier, T. Voss, I. Rückmann and J. Gutowski, Nanotechnology 19, 135705 (2008).

[20] L. Wischmeier, T. Voss, S. Börner and W. Schade, Appl. Physics A 84, 111 (2006).

[21] V.V. Travnikov, A. Freiberg and S.F. Savikhin, J. Luminescence 47, 107 (1990).

[22] M. Biswas, Y. S. Jung, H. K. Kim, K. Kumar, G. J. Hughes, S. Newcomb, M. O. Henry, and E. McGlynn., Physical Review B 83, 235320 (2011).

[23] S. Kuehn, S. Friede, S. Sadofev, S. Blumstengel, F. Henneberger and T. Elsaesser, Appl. Phys. Lett. 103, 191909 (2013).

[24] J. P. Richters, T. Voss, D.S. Kim, R. Scholz and M. Zacharias, Nanotechnology 19, 305202 (2008).

[25] Y. Chen, Y. Pu, L. Wang, C. Mo, W. Fang, B. Xiong, F. Jiang., Mat. Sc. Semicond. Processing 8 (4), 491 (2005).

[26] K. Samanta, A. K. Arora, S. Hussain, S. Chakravarty and R.S. Katiyar, Current Applied Physics 12 (5), 1381 (2012).

[27] J. Fan, Y. Hao, C. Munuera, M. García-Hernández, F. Güell, E. M. J. Johansson, G. Boschloo, A. Hagfeldt, and A. Cabot., J. Phys. Chem. C 117 (32), 16349 (2013).

[28] S. Wang, F. Su, Chi-Chung Ling, W. Anwand and A. Wagner, J. Appl. Phys. 116, 033508 (2014).

[29] M.H. Weber, N. S. Parmar, K.A. Jones and K.G. Lynn, J. Electron. Mater 39 (5), 573 (2010).

[30] L. E. Halliburton, N. C. Giles, N. Y. Garces, Ming Luo, Chunchuan Xu, Lihai Bai and L. A. Boatner, Appl. Phys. Lett. 87, 172108 (2005).

[31] T. Moe Børseth, B. G. Svensson, A. Yu. Kuznetsov, P. Klason, Q. X. Zhao and M. Willander, Appl. Phys. Lett. 89, 262112 (2006).

[32] B. K. Meyer, H. Alves, D. M. Hofmann, W. Kriegseis, D. Forster, F. Bertram, J. Christen, A. Hoffmann, M. Straßburg, M. Dworzak, U. Haboeck and A. V. Rodina, Phys. Stat. Solidi (b) 241, No. 2, 231 (2004).

[33] M. Schirra, R. Schneider, A. Reiser, G. M. Prinz, M. Feneberg, J. Biskupek, U. Kaiser, C. E. Krill, K. Thonke, and R. Sauer, Phys. Rev. B 77, 125215 (2008).

[34] T. Voss, J. P. Richters and A. Dev, Phys. Stat. Solidi (b) 247, 2476 (2010).

[35] C.H. Ahn, Y.Y. Kim, D.C. Kim, S.K. Mohanta, and H.K. Cho, Journal of Applied Physics 105, 013502 (2016) 
[36] L.L Yang, Q.X. Zhao, M. Willander, J.H. Yang, and I. Ivanov, J. Appl. Phys. 105, 053503 (2009).

[37] L. Zhang, D. Wett, R. Szargan, and T. Chassé., Surface and Interface Analysis 36, 1479 (2004).

[38] Z.G. Wang, X.T. Zu, S. Zhu and L.M Wang, Physica E 35, 199 (2006).

[39] D. E. Pugel, R. D. Vispute, S.S. Hullavarad, T. Venkatesan anb B. Varughese, Applied Surface Science 254, 2220 (2008).

[40] J. Duchoslav, R. Steinberger, M. Arndt, and D. Stifter, Corrosion Science 82, 356 (2014).

[41] M. Wang, Y. Zhou, Y. Zhang, S. H. Hahn and E. J. Kim, CrystEngComm 13, 6024 (2011). 


\section{Figure captions}

Figure 1 : Schematic view of a sealed ampoule, prepared for the annealing under zinc vapor

Figure 2 : SEM images of $\mathrm{ZnO}$ nanowires : (a) as-grown, (b) post-annealed with $\mathrm{Zn}$ at $700{ }^{\circ} \mathrm{C}$, (c) post-annealed without $\mathrm{Zn}$ at $700{ }^{\circ} \mathrm{C}$.

Figure $3 \mathrm{PL}$ spectra measured at $5 \mathrm{~K}$ for $\mathrm{ZnO}$ nanowires samples: a) as grown, b) treatment at $580{ }^{\circ} \mathrm{C}$ under $\mathrm{Zn}$ source (insert : $\mathrm{ZnO}$ crystal), c) near band edge emission of as-grown (black), and deep level emissions of as-grown (red) and annealed at $620^{\circ} \mathrm{C}$ (blue). For DLE bands, the PL integration time has been increased and filters changed to enhance the signals

Figure 4 : Peak fitted XPS $\mathrm{O}_{1 \mathrm{~s}}$ spectra for different treatments: (a) as grown, (b) post-annealed at $550{ }^{\circ} \mathrm{C}$, (c) post-annealed at $620^{\circ} \mathrm{C}$, (d) exposed to air for 2 month after treatment at $620{ }^{\circ} \mathrm{C}$.

Figure 5 : Intensity ratio between $(533.3 \mathrm{eV})$ - and $(531 \mathrm{eV})-\mathrm{O}_{1 \mathrm{~s}}$ peaks for the different treated samples

\section{Tables}

Table 1 Quantification of XPS Zn2p3/2, O1s, and C1s peak (atm.\%) 